Article

\title{
A Bibliometric Analysis of Literature on Vegetable Prices at Domestic and International Markets-A Knowledge Graph Approach
}

\author{
Youzhu Li ${ }^{1}$, Jinsi Liu ${ }^{1}$, Hongyu Yang ${ }^{1}$, Jianxin Chen ${ }^{2, *}$ and Jason Xiong ${ }^{3}$ \\ 1 College of Public Administration, Huazhong Agricultural University, Wuhan 430070, China; \\ liyz@mail.hzau.edu.cn (Y.L.); louis.hzau.edu.cn@webmail.hzau.edu.cn (J.L.); \\ yanghy.hzau.edu.cn@webmail.hzau.edu.cn (H.Y.) \\ 2 College of Art and Design, Wuhan University of Technology, Wuhan 430070, China \\ 3 Walker College of Business, Appalachian State University, Boone, NC 28607, USA; xiongjj@appstate.edu \\ * Correspondence: chenjianxin@whut.edu.cn
}

check for updates

Citation: Li, Y.; Liu, J.; Yang, H.; Chen, J.; Xiong, J. A Bibliometric Analysis of Literature on Vegetable Prices at Domestic and International Markets-A Knowledge Graph Approach. Agriculture 2021, 11, 951. https: / / doi.org/10.3390/ agriculture11100951

Academic Editor: Gioacchino Pappalardo

Received: 1 September 2021

Accepted: 27 September 2021

Published: 30 September 2021

Publisher's Note: MDPI stays neutral with regard to jurisdictional claims in published maps and institutional affiliations.

Copyright: (C) 2021 by the authors. Licensee MDPI, Basel, Switzerland. This article is an open access article distributed under the terms and conditions of the Creative Commons Attribution (CC BY) license (https:// creativecommons.org/licenses/by/ $4.0 /)$.

\begin{abstract}
Vegetable prices play an important role in people's daily lives globally. However, there is very little research that has systematically analyzed and discussed the existing research. Therefore, in order to narrow this gap in the literature, there is a need for an extensive and macro-level study of vegetable price research. By sorting out a large volume of documents, This paper presents a visual representation of the vegetable price research literature in the Web of Science and CNKI databases; it includes three perspectives of the cooperative network, co-occurrence network and co-cited network, and draws scientific knowledge map, to acquire a good understanding of the current situation of vegetable price research, hot issues, clearly shows the focus of the research, summaries the fluctuation pattern of vegetable price, deeply analyses the influencing factors of vegetable price fluctuation, and find out the connection between related scholars and the correlation existing in each research content. The results show that scholars at home and abroad have conducted research from the perspectives of vegetable price influencing factors, forecasting and early warning, and insurance systems, but they are only limited to some regions, and some vegetable varieties, and the forecasting and early warning of vegetable prices are not accurate enough, the insurance system is not perfect, and a complete price influencing mechanism has not yet been proposed. The aim of this study is to make a significant contribution to the scientific community and industry practitioners by providing a comprehensive understanding of the latest status, popular keywords and topics, and emerging areas of vegetable price research. In addition, this study will be a useful and valuable reference and guide for researchers interested in this field.
\end{abstract}

Keywords: vegetable price; knowledge graph; visualization; cluster analysis

\section{Introduction}

China is the world's largest producer and consumer of vegetables; the total output value of vegetables has surpassed the total output value of grains, becoming the most important agricultural product worthy of the name [1]. In recent years, people's living standards have improved significantly, thus boosting the demand for diversified and highquality vegetables. The rapid progress of the refrigeration and logistics transportation industry, the further development of the international market and the emergence of online vegetable sales show strong development potential. These are new opportunities facing the vegetable industry, and the vegetable industry has ushered in a rapid development situation. However, it is also facing more and more challenges [2]. The increase in vegetable price volatility is affected by inherent time series, natural disasters and the uniqueness of the vegetable itself, and the substitution and integration of different vegetables. Recent examples of garlic, ginger, bean and onions show that the price of vegetables has risen 
abnormally. The high vegetable price could negatively affect the consumers [3]. This further hurt vegetable farmers, causing them to suffer heavy losses or even bankruptcy. With increased operating risks and reduced profits, many vegetable farmers have turned to other industries. Therefore, the government should formulate relevant policies to adjust the abnormal fluctuation of vegetables. It is critical to ensure vegetables at moderate prices, and vegetable farmers can profit. Of course, apart from China, other countries and regions are also very concerned about the increase in vegetable prices, especially as governments have repeatedly introduced incentives and subsidies to stabilize vegetable prices and ensure that people can afford to consume vegetables. At present, few scholars have a systematic literature review of vegetable price research, nor have they put together a comparative study of vegetable price research in China and other countries, let alone synthesize the research hotspots and outlooks in this research area. Therefore, this paper presents a visualization of a large amount of literature and summarizes the fluctuation pattern of vegetable prices, aiming to provide a reference for scholars' vegetable price research and governmental decision making.

Traditional review research, in which scholars need to read as much literature as possible in order to achieve an understanding of the field, is largely influenced by the amount of literature read, the cognitive perspective, the background of the scholar and other factors and the conclusions drawn are somewhat subjective. With the generation of massive amounts of data, the traditional inductive summary method becomes difficult to adapt to current research, so academics need a more scientific review research tool. This paper uses the software CiteSpace 5.4.R1 (Software Sources: http:/ / cluster.ischool.drexel. edu/ cchen/citespace/download/) (accessed on 20 September 2021), whose design soul is derived from structural hole theory and optimal information foraging theory [4]. That is, exposure to information, opinions or views that are largely broad-spectrum and diverse; the software uses this theory to find nodes with a high degree of mediating centrality, focusing on the role of the academic field in its overall development. From the data sources, this paper focuses on the comparison of vegetable price research reviews in China and other countries, so the most representative databases are selected, one is China Knowledge Network, and the other is the international Web of Science database, the results of research on vegetable prices are basically concentrated in these two databases, and the research results are widely representative. In addition, the use of comparative research can highlight the theme of this paper more.

\section{Literature Sources and Research Methods}

\subsection{Literature Source}

Compared with other literature reviews [5], this research not only visualizes the research on vegetable prices in China but also visualizes the research on vegetable prices in other countries. In terms of data selection for the research on vegetable prices in China, compared with many databases, CNKI database is the most complete. It covers the research progress of Chinese scholars on vegetable prices. Therefore, I chose to search for "vegetable prices" on CNKI. The period is from 1992 to 2021, which is 29 years. After screening, a total of 2901 copies were determined, as shown in Figure 1. In the analysis of data from other countries, the core collection on the Web of Science page was utilized, and keywords "vegetable prices" were used in the basic search bar to search for topics. The time span is 1900-2021, and the search returned 2168 copies. Then "document type" was set to ARTICLE", 1776 documents were identified. Finally, 490 papers were selected, matching the research of this article through "Correlation", exported the Refworks text data to a txt format file, and used CiteSpace software to analyze the selected documents. 


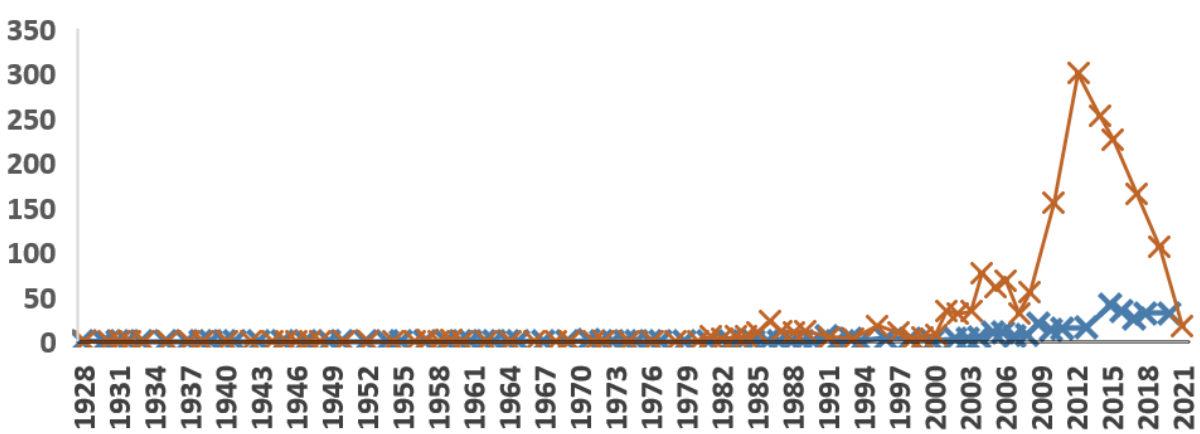

Figure 1. Statistical Chart of Publications.

Table 1 research in China started relatively late. After 1978, research began to rise. The reason is that after the reform and opening up in 1978, the market economy was implemented, and vegetable prices frequently fluctuated, which caused the whole society and Scholars' concern about this. Other countries started earlier and have already achieved certain research results [6]. During the past 20 years, there have been more Chinese scholars that focused on vegetable prices research [7]. The reason is that vegetable prices fluctuate sharply, which has seriously affected people's lives.

Table 1. Ranking of WOS Cooperative Citations.

\begin{tabular}{cccccc}
\hline Id & Freq & $\mathbf{X}$ & $\mathbf{Y}$ & Au & Py \\
\hline 0 & 92 & 50 & 45 & USA & 1931 \\
1 & 49 & -382 & 285 & PEOPLES R CHINA & 1991 \\
2 & 27 & -465 & -129 & GERMANY & 1998 \\
3 & 26 & -712 & 311 & AUSTRALIA & 2002 \\
4 & 18 & -288 & -48 & ENGLAND & 1995 \\
5 & 16 & -560 & 11 & INDIA & 2015 \\
6 & 14 & 17.34 & 405.14 & JAPAN & 1991 \\
7 & 13 & -838 & -101 & FRANCE & 2008 \\
\hline
\end{tabular}

\subsection{Research Method}

This research utilizes the bibliometric method to visualize the literature over the years. Meta-analysis is a research method that takes the existing literature as the object of study and uses statistical and other methods of measurement to study the distribution structure and quantitative relationships of literature and intelligence. It then discusses the hot spots of research in a certain field, which to a certain extent overcomes the subjectivity of traditional literature reviews and has the advantages of being efficient, timesaving and scientific. Of course, there are limitations to the method, as it is influenced by the size of the sample, the quality of the literature, the criteria used for selection and the measurement is limited to the output of published papers, ignoring work in progress in research. Therefore, there is a need to control the quality of the sample size and to use scientific means to improve accuracy wherever possible. CiteSpace software is favored by most scholars due to its simple operation, powerful functions and good visualization effects [8]. This tool is suitable for complex network analysis across time, diversity and dynamics. It can show the documents of a period through different dimensions and find its inner logic more intuitively. At the same time, the full-text text data of the selected literature for analysis was analyzed. RStudio software was used to analyze the high-frequency words that appear in the text. Then, Python software was used to perform cluster analysis. This provides more information about which aspects scholars are mainly concerned about vegetable prices. 


\section{Visual Analysis}

3.1. Analyze Authors, Institutions and Countries to Generate a Cooperative Network Analysis Diagram

First, data from the Web of Science was cleaned and imported into the CiteSpace software. Author, Institution and Country options of the cooperative network analysis section were checked. Then, the network was divided into 17 larger common citation clusters, as shown in Figure 2. Cooperative networks are derived from the principles of cluster analysis and refer to the analytical process of grouping a collection of physical or abstract objects into multiple classes consisting of similar objects, based on the similarity of the objects being analyzed.

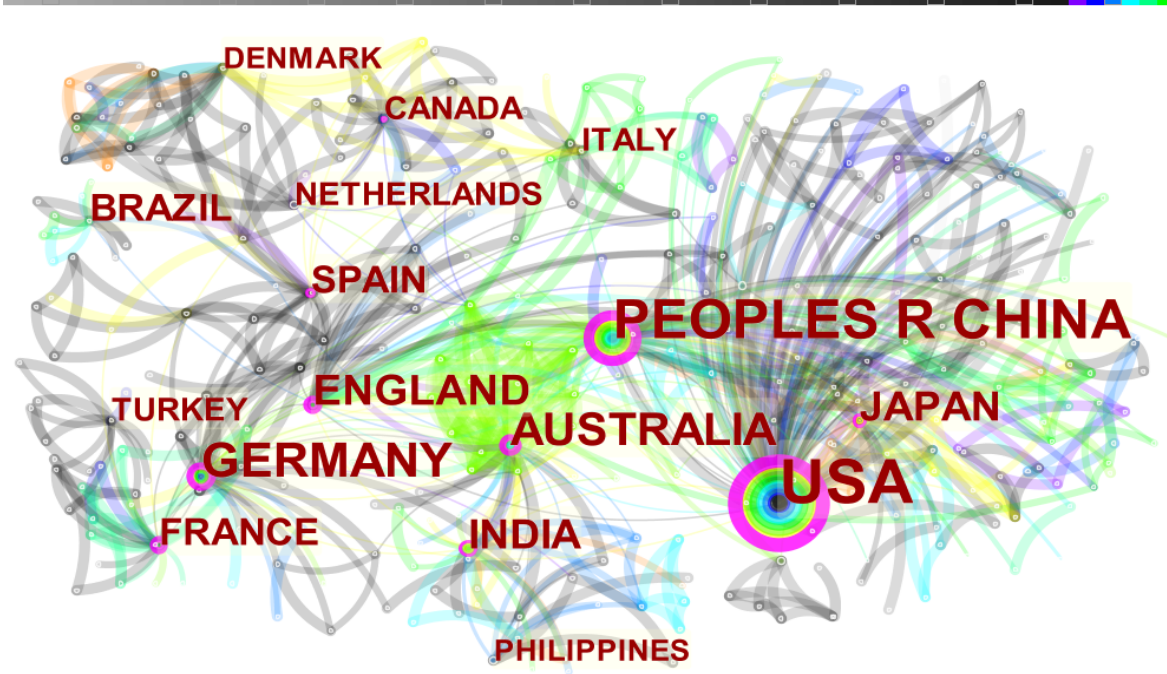

Figure 2. Analysis Diagram of WOS Cooperation Network.

As shown in Figure 2, different countries have formed different clusters. There are also relationships between the clusters. This indicates that the research on vegetable prices in different countries has different focuses, but there are similar parts. Index terms from their citations mark these clusters, and a ranking of the number of cooperative citations is generated, respectively, as shown in Table 1. From a global perspective, there is a clustering phenomenon in the research on vegetable prices in various countries, and there is a relatively obvious geographical distribution. For example, the United States, China, Japan, Australia, India, the Philippines and other countries have close research links; secondly, some European countries, Germany There are research clusters in countries such as the United Kingdom, France and Turkey. The reason is that geographical location, climatic conditions, eating habits and other factors are relatively consistent. Therefore, the research on vegetable prices is similar. The United States has a relatively large node. Due to factors such as marketing channels, changes in market structure, pricing and promotional activities, the price fluctuations of vegetables in the United States are complicated, and research on them is relatively extensive. The author found through combing China's vegetable import and export volume in 2019 that India, the United States and Vietnam are the top importers, with imports of 160,770.7 tons, 101,398.2 tons and 98,058.77 tons, respectively; China's vegetable exporting country ranks first in Japan, Vietnam, South Korea and the United States, the export volumes were 1,482,830.82 tons, 1,297,714.25 tons, 1,139,059,39 tons and 47,2093.57 tons (Data Sources: https://bg.qianzhan.com/) (accessed on 9 September 2021). It is obvious that China's vegetable imports and exports are in a trade surplus. A review of the relevant literature found that there is little research on this at present.

Based on Table 1, in the vegetable price research, the top countries are the United States, China, Germany, Australia, the United Kingdom, India and Japan. The analysis 
of the influencing factors of vegetable prices has carried out a lot of research in many countries, which is enough to show that vegetables play an important role in people's dietary life in various countries. In recent years, people have been pursuing a healthy life [9], and people's attention to vegetables is gradually greater than food. Especially the large populations and vast areas of the above countries have increased the contradiction between the supply and demand of vegetables [10]. Comparing the retail prices of more than 600 kinds of food in more than 100 countries and regions around the world, it is found that the cost of vegetables is at the forefront, which directly affects people's daily lives. This is also the reason why scholars are keen to study vegetable prices.

The data downloaded by CNKI was then converted. The original data was translated and then analyzed via the CiteSpace software, as shown in Figure 3.

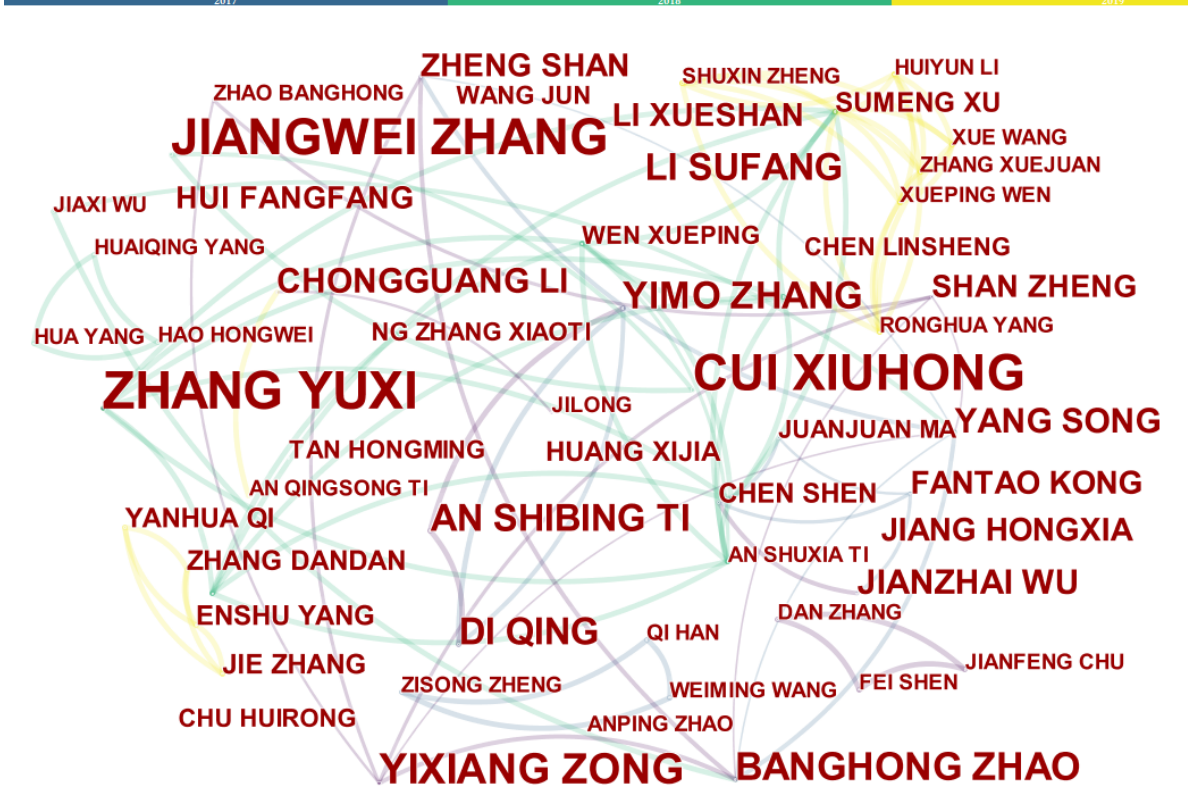

Figure 3. CNKI Cooperation Network Analysis Diagram.

The main group network is divided into seven larger co-citation clusters, which are marked by index terms from their own citations. As shown in Table 2, they generate a ranking of the number of cooperative citations.

Both Beijing Xinfadi Agricultural Products Co., Ltd. and China Agricultural Products Market Association are publishing units. They have been studying vegetable prices since 1994 and have analyzed Beijing vegetables every quarter since January 2009. The third rank is the School of Economics and Management of Huazhong Agricultural University. Many authors have emerged from this publication. It can be seen that there have been fruitful results in vegetable price research. The fourth is Beijing the Price Monitoring Center of the Municipal Development and Reform Commission has commented on Beijing's vegetable prices and its wholesale price index since 2015. The fifth place is the Plantation Management Department of the Ministry of Agriculture, which has analyzed and studied Chinese vegetables since 2012. Crops are affected by pests and diseases, and weather, especially the impact of Typhoon Lekima in 2019 on Shouguang vegetables in Shandong Province, which has also attracted the attention and research of scholars. Zhou Zifang is also on the list, mainly studying Jiangnan fruits and vegetables from 2011. There are 18 price indices in 2016. Lin Weijun was mainly engaged in research on the vegetable industry in Guangdong from 2008 to 2016, and there were 26 in total. It can be seen from the cooperation center table that the most influential ones are cluster \#1 and cluster \#4. There is a strong cooperative relationship within them, and excellent scholars can also increase the reputation of the corresponding publishing organization. 
Table 2. Ranking of CNKI Cooperative Citations.

\begin{tabular}{|c|c|c|c|c|}
\hline Id & Freq & $\mathbf{X}$ & $\mathbf{Y}$ & Au \\
\hline 0 & 97 & -188.99 & 63.77 & Beijing Xinfadi \\
\hline 1 & 41 & -130.33 & 44.95 & China Agricultural Products Market Association \\
\hline 2 & 37 & -197.81 & -63.2 & School of Economics and Management, Huazhong Agricultural University \\
\hline 3 & 37 & -329.68 & 46.93 & Price Monitoring Center of Beijing Municipal Development and Reform Commission \\
\hline 4 & 32 & -51.1 & 71.67 & Department of Planting Management, Ministry of Agriculture \\
\hline 5 & 28 & -234.57 & 253.82 & School of Economics and Management, China Agricultural University \\
\hline 6 & 23 & -224.36 & -34.42 & Li Chongguang \\
\hline 7 & 20 & -302.85 & 91.81 & Cui Xiuhong \\
\hline 8 & 19 & -99.14 & 191.52 & Kong Fantao \\
\hline 9 & 18 & -241.8 & 178.87 & Mu Yueying \\
\hline 10 & 14 & -356.37 & 92.55 & Zhang Jiangwei \\
\hline 11 & 14 & 132.75 & 192.27 & Zhou Zifang \\
\hline 12 & 14 & 52.45 & 43.56 & Lin Weijun \\
\hline 13 & 12 & -152.23 & -1.05 & Song Changming \\
\hline
\end{tabular}

\subsection{Analysis of Keywords, Sources and Categories to Generate a Co-Occurrence Network Diagram}

Similarly, after processing the data of Web of Science, the data was imported to the CiteSpace software, and the Keyword, Term and Source options of the co-occurrence network sections were checked. The network is divided into 16 co-citation clusters. These clusters are determined by their Index term citation mark, as shown in Figures 4 and 5. The co-occurrence network is based on the principle of co-occurrence analysis, which means that a group of words is counted two by two for the number of times they appear in the same set of documents. This number of co-occurrences measures the affinity between them. It is a significant improvement over the most common word frequency analysis. Of course, it needs to follow two basic assumptions: 1 . The scholar can choose the title, abstract, and keywords scientifically, and these parts also cover the central idea of the whole text; 2 . If enough scholars talk about mentioning the same keyword or study the same direction, it indicates that the object has robust research significance in the field of study.

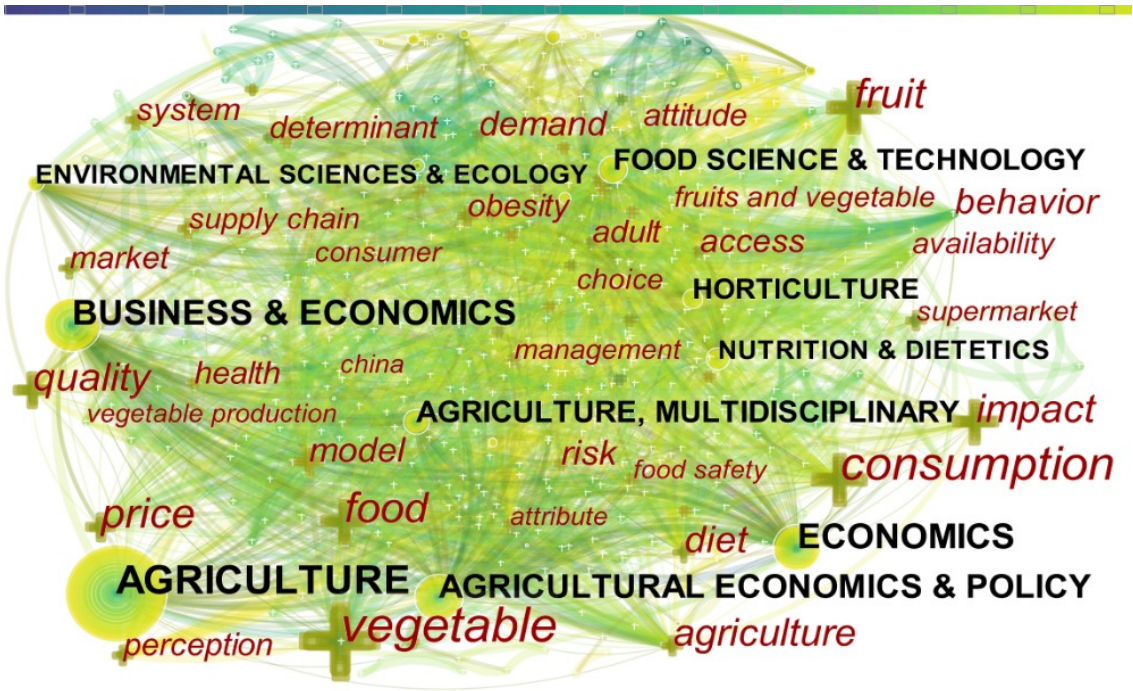

Figure 4. WOS Keyword Co-occurrence Network Diagram. 
Top 9 Journals with the Strongest Citation Bursts

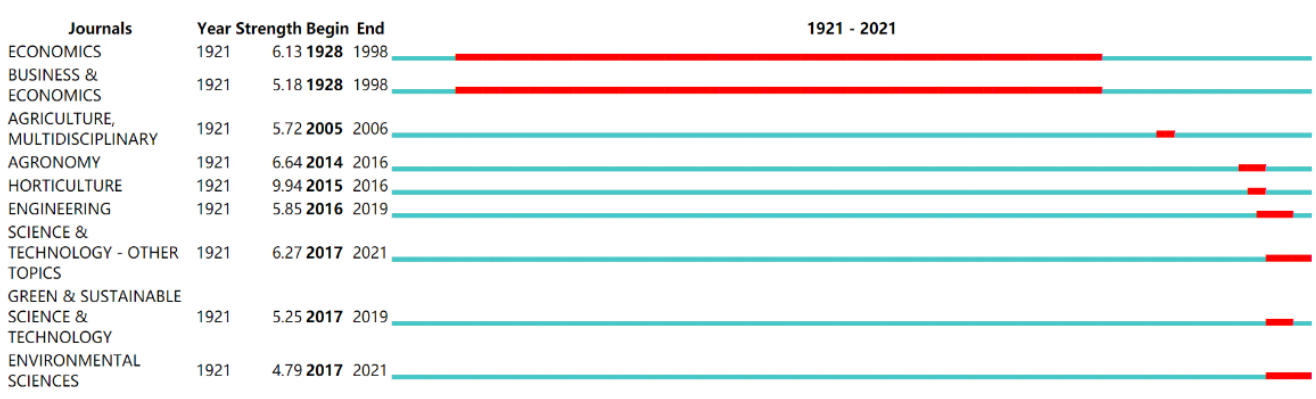

Figure 5. The Evolution of WOS Vegetable Price Research.

As shown in Figures 4 and 5, the black font indicates that the sources of related journals are ranked in the forefront, such as AGRICULTURE, BUSINESS \& ECONOMICS, AGRICULTURAL TURAL ECONOMICS \& POLICY, etc., indicating that these journals are in the forefront of vegetable price research. The research evolution diagram is based on the principle of emergence analysis. The sudden appearance and increasing number of new things at a certain time and using this method indicate which journals are concentrated in this research area and, of course, predict future trends. It can be seen from the research evolution graph that as time progresses, relevant journals pay more and more attention to the research on vegetable prices. In contrast, the attention of other journals has fallen. The ranking of the number of co-occurrence citations generated (see Table 3) shows that in the research, in addition to vegetables, the price of fruits is also concerned [11]. "Consumption" ranks second, which is enough to show that consumption involves daily life, so its attention has been high.

Table 3. Ranking of WOS Co-occurrence Citations.

\begin{tabular}{cccccc}
\hline Id & Freq & X & Y & Au & Py \\
\hline 0 & 57 & -405 & 339 & Vegetable & 1993 \\
1 & 43 & -172 & 289 & Consumption & 1999 \\
2 & 30 & -512 & 318 & Price & 2004 \\
3 & 30 & -140 & 194 & Food & 2001 \\
4 & 29 & -168 & 246 & Fruit & 2001 \\
5 & 24 & -376 & 191 & Quality & 2009 \\
6 & 24 & -229 & 330 & Impact & 2011 \\
7 & 21 & -333 & 366 & Agriculture & 2000 \\
\hline
\end{tabular}

Judging from the perspective of the number of citations and centrality, WOS research focuses on the development of agriculture, which extends to the agricultural economy, and the development of the agricultural economy needs the support of agricultural policies. By consulting the literature, some academics have linked vegetables to health, based on the increasing emphasis on the role of vegetables in health, the production of green organic vegetables and the increased consumption of vegetables, which has contributed to the rise in vegetable prices [12]. Therefore, the Government advocates the production of green and organic vegetables on the one hand and actively introduces policies to stabilize vegetable prices and promote vegetable consumption on the other [13].

The data of Keyword, Term and Source downloaded from CNKI was analyzed. Keyword co-occurrence network diagram was provided in Figures 6 and 7. 


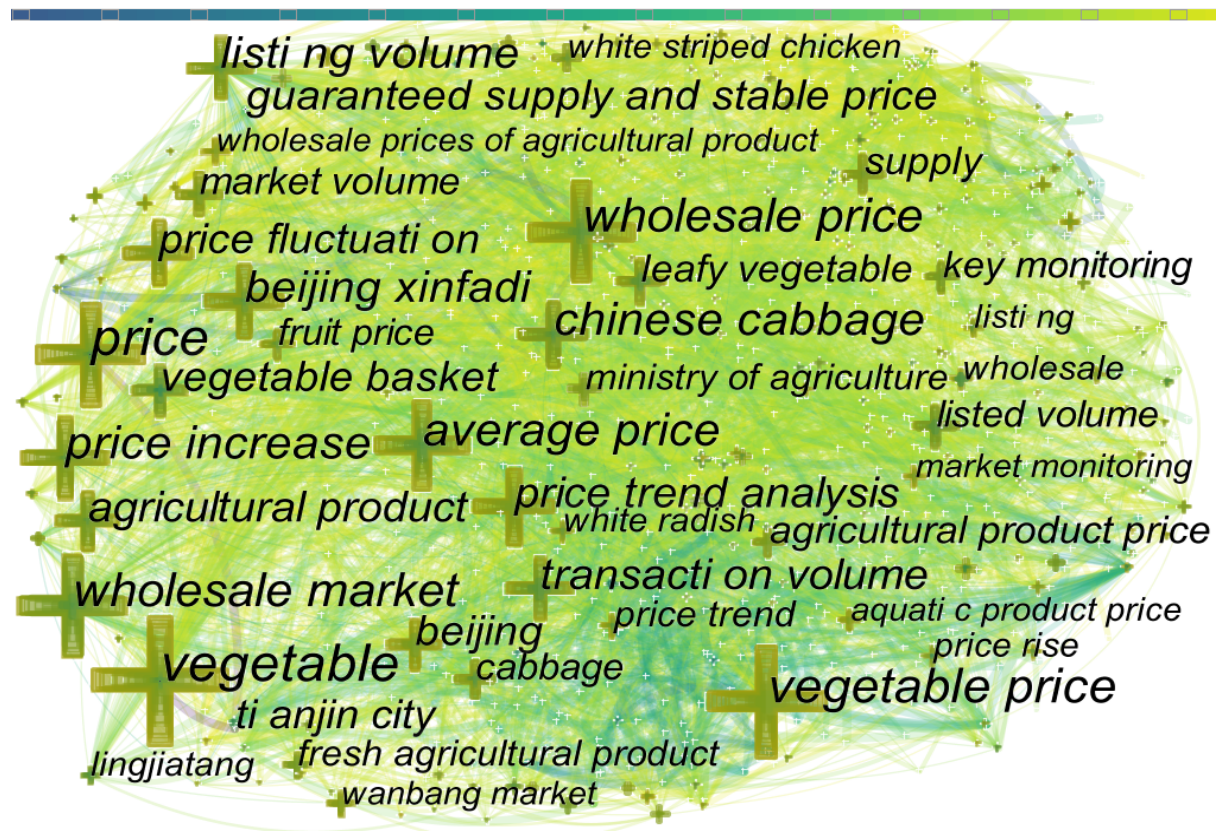

Figure 6. CNKI Keyword Co-occurrence Network Diagram.

Top 15 Keywords with the Strongest Citation Bursts

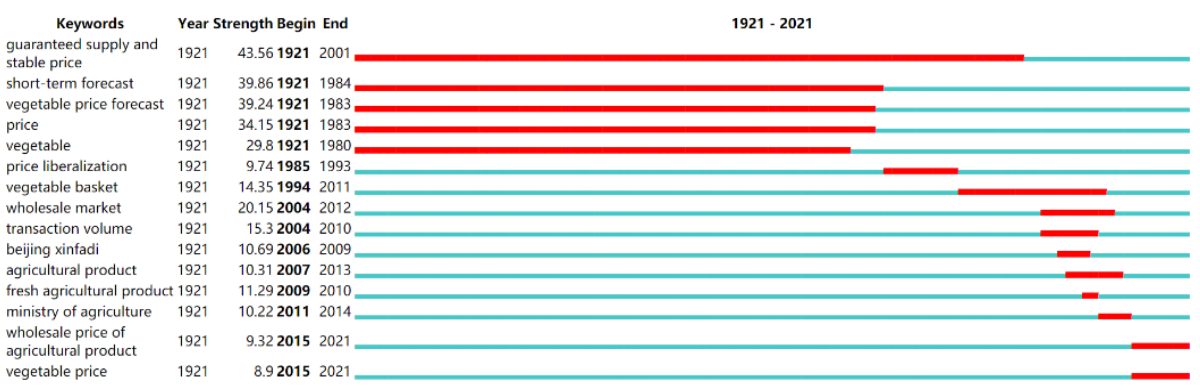

Figure 7. The Evolution of CNKI Vegetable Price Research.

We can intuitively see that some keywords are in key positions, indicating that they occupy an important position through the analysis of keywords. Compared with the unified research on vegetable prices, domestic research focuses on the fluctuation factors of vegetable prices and the three major relationships between vegetable farmers, the government and consumers, and use this to conduct discussion and research. Table 4 is the ranking of the number of co-occurrence citations generated. Citation counting is the most intuitive comparison method. The top keywords are the key research of many scholars, which highlights their importance. The first four are "Vegetable", "Price", "Vegetable Price" and "Wholesale Market". Obviously, they are closely related to the subject of this research. It shows from the side that vegetable price has always been the central issue studied by many scholars, and it is also a long-term need. Solve the clarified propositions. The three "Beijing Xinfadi", "Price Trend Analysis" and "Price Fluctuation" are sufficient to show that the domestic vegetable price index and prediction system in Beijing have formed a set of systems. The reasons are analyzed: First, the relevant researchers, Therefore, it is necessary to track and study vegetable prices in Beijing for a long time. Second, Beijing is the capital of China, and its important position is self-evident. Therefore, real-time research on vegetable prices is necessary. "Vegetable Farmer", "Average Price", "Transaction Volume", "Wholesale Price" and so on are directly related to the research on vegetable prices. The price level directly affects the interests of consumers and producers. 
Table 4. Ranking of CNKI Co-occurrence Citations.

\begin{tabular}{ccccc}
\hline Id & Freq & $\mathbf{X}$ & $\mathbf{Y}$ & Au \\
\hline 0 & 279 & 392 & 176 & Vegetable \\
1 & 264 & -68 & 349 & Price \\
2 & 179 & -372 & 372 & Vegetable Price \\
3 & 165 & -347 & 323 & Wholesale Market \\
4 & 160 & -348 & 121 & Wholesale Price \\
5 & 134 & 117 & 185 & Price Increase \\
6 & 128 & 201 & 132 & Chinese Cabbage \\
7 & 127 & -373 & 166 & Average Price \\
8 & 113 & -48 & 23 & Beijing Xinfadi \\
9 & 101 & -331 & 408 & Agricultural Product \\
10 & 99 & -274 & -194 & Transaction Volume \\
11 & 95 & -46 & 247 & Price Trend Analysis \\
12 & 87 & -362 & 241 & Price Fluctuation \\
\hline
\end{tabular}

From the ranking of the number of emergencies, these are events that have a relatively large impact on vegetable prices at certain times and in certain areas, resulting in a continuous fermentation process. Many scholars have invested in them in order to grasp the ins and outs of the incident in time. Find out the real reason behind it and provide a feasible basis for government decision-making. In the centrality rankings, researchers are more inclined to study the price comparison of vegetables over the same period, the supply chain of vegetables, the wholesale price of vegetables and the month-on-month rise in prices. The research perspective is more detailed and specific, and they are more directly concerned with the impact of the transmission of vegetable price fluctuations. Factors, this is inseparable from China's domestic environment.

\subsection{Analyze Reference and Cited Author to Generate a Co-Citation Analysis Graph}

The data dimensions obtained by CNKI are less than those obtained by WOS, including only authors, titles, source journals, keywords, abstracts, etc. There are no references behind each article, so co-citation analysis cannot be carried out. Import WOS into CiteSpace software, check the co-citation analysis module and acquire the analysis as follows in Figure 8. In this co-citation analysis, it is important to clarify that "citations" refer to the references that follow the paper and that the internal logic is that the cited and current literature are relevant in terms of content. This is based on the assumption that scholars cite other people's literature to indicate support for other people's views, either by directly citing other people's research or by exploring further on the basis of other people's research. Co-citation analysis refers to the fact that if two pieces of literature appear together in the bibliography of the third piece of literature, then these two pieces of literature form a co-citation relationship.

The network graph is divided into 10 common citation clusters, which are marked by index terms from their own citations. The top clusters are "USDA", "EUR J COMMUN", "UN", etc., indicating that these institutions and organizations have been cited more frequently in the literature on vegetable price research and generated a ranking of cooccurrence citations (Table 5).

The above is an analysis from the references and authors of the selected documents. Citation analysis is to analyze the citation and citation phenomenon of the analyzed object to reveal the leading scholars in this field and gain the recognition of other scholars. Regardless of citation count or centrality, Carter et al., (2010) has been cited more frequently. He believes that vegetable prices directly affect people's intake of vegetables, which in turn is related to the risk of diabetes [14]. Bacus et al., (2015) found that Philippine smallholder farmers improve the quality of vegetables, conducive to entering high-value markets and increasing income [15]. Powell et al., (2013) analyzed tax relief and subsidies as an important policy to adjust consumers The diet structure increases the consumption of vegetables [16]. Drewnowski and Darmon (2005) found that people are highly sensitive to 
vegetable prices, and effective regulation of vegetable prices can improve people's quality of life [17]. Cassady et al., (2007) designed the changes in vegetable price to be investigated in 25 supermarkets in three time periods. T study found that the high prices of vegetables were the main obstacle to their consumption [18]. Through the above methods, the foreign literature has been sorted out from different angles. The research on vegetable prices mainly focuses on some angles to carry out research by reading the relevant literature.

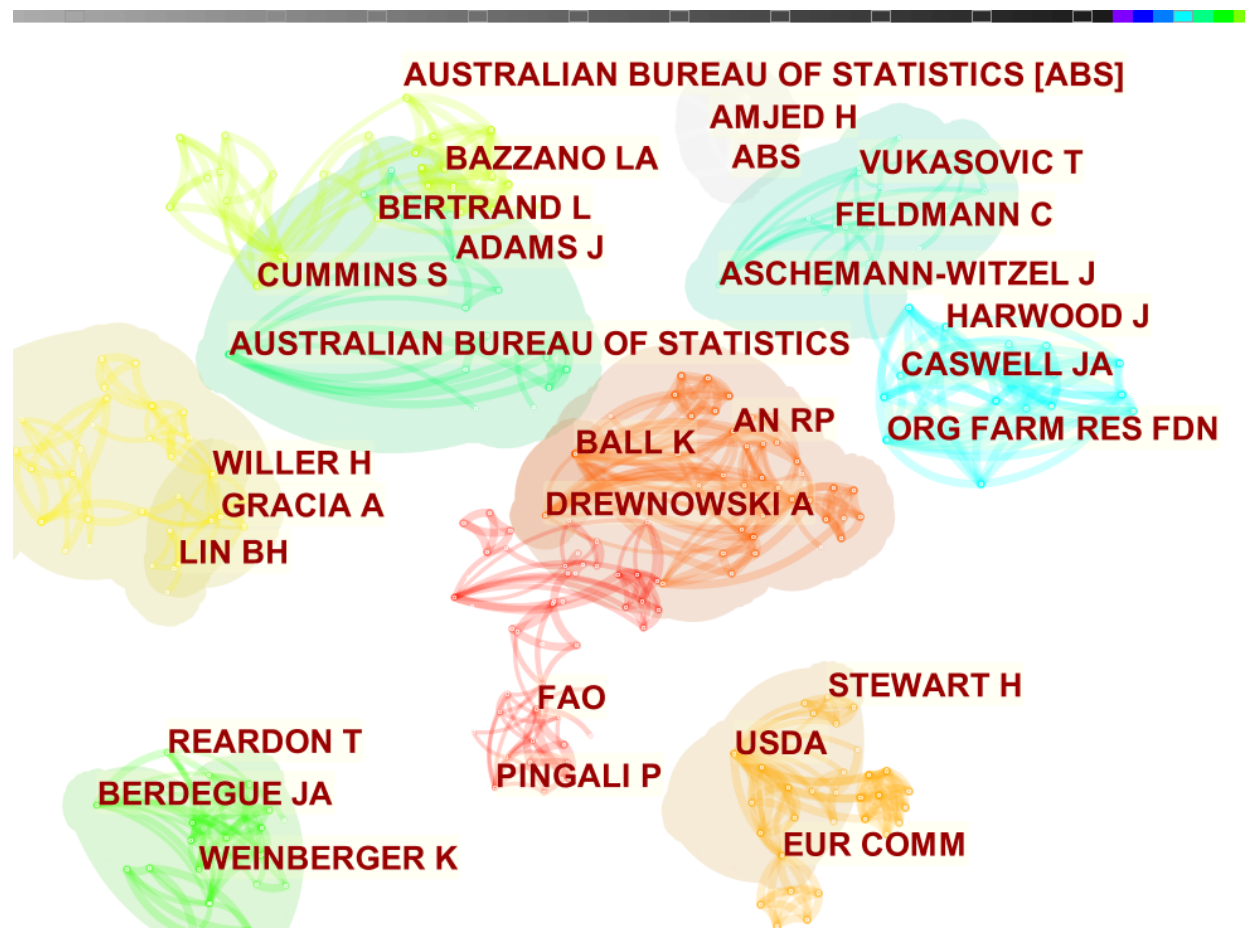

Figure 8. WOS Co-citation Analysis Diagram.

Table 5. Ranking of WOS Co-occurrence Citations.

\begin{tabular}{cccccc}
\hline Id & Freq & $\mathbf{X}$ & $\mathbf{Y}$ & Au & Py \\
\hline 0 & 5 & 272.89 & -171.51 & USDA & 2014 \\
1 & 5 & 377.93 & -207.35 & EUR J COMMUN & 2007 \\
2 & 5 & 326 & 21 & UN & 2011 \\
3 & 4 & -78.91 & -51.23 & Davies & 2010 \\
4 & 4 & -21.6 & -95 & Montiflor & 2015 \\
5 & 4 & -376 & 191 & Powell LM & 2009 \\
6 & 3 & -229 & 330 & Drewnowski A & 2011 \\
7 & 2 & -333 & 366 & Cassady Diana & 2007 \\
\hline
\end{tabular}

\section{Visual Cluster Analysis}

The previous article mainly analyzes the text data such as titles, authors, abstracts and references downloaded from CNKI and WOS. It may not be enough to fully understand the article's content that scholars specifically emphasize and research. Therefore, the author uses all Chinese and foreign text data for analysis, first uses RStudio software to clean up the data, uses stop words, removes irrelevant numbers, symbols and other common words, and finally selects the top 53 phrases (Figure 9). 


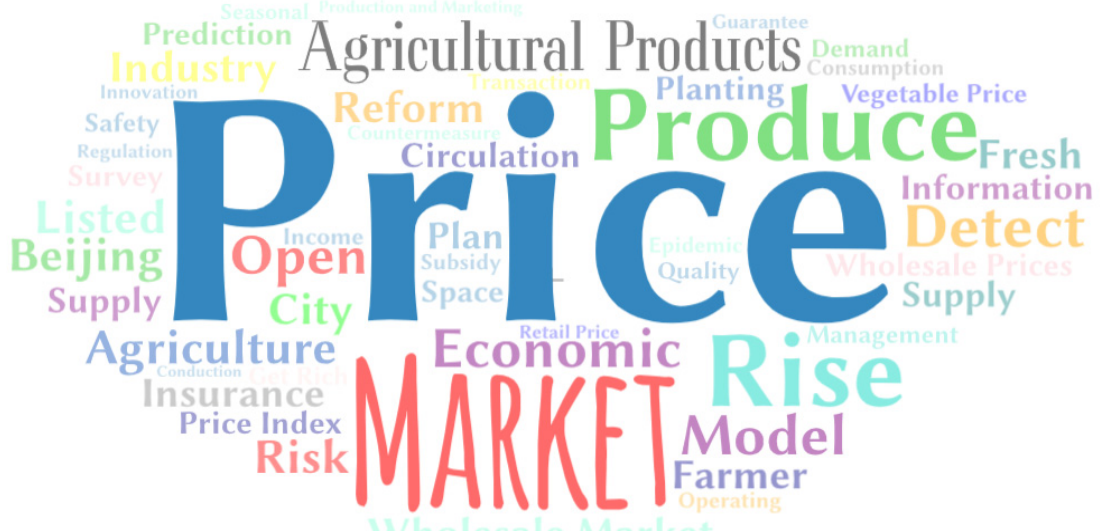

Figure 9. Statistics of High-frequency Words.

It can be seen from the figure that the larger the letter, the greater the frequency of the word. Words such as "Price", "Market", "Agricultural Products", "Produce" and "Agriculture" are in the forefront. This is also well understood, because the so-called vegetable price comes from the market and also from agricultural production. Of course, the word "Rise" also shows that in most cases, the reason for the research on vegetable prices is that the price of vegetables has risen. This shows that the interests of consumers are more important in the research process because compared to vegetable farmers, consumers are a larger group. However, this also suggests that scholars should pay more attention to the low price of vegetables, and it is particularly important to protect the interests of vegetable farmers. Next, the author conducts a cluster analysis on the 53 selected phrases. In this paper, the FCM clustering algorithm is used, and the reference Formulas (1) and (2) are as follows, where $V$ is the clustering center and $m$ is the weighted index. After calculation, the following clustering diagram is generated (Figure 10).

$$
\begin{gathered}
(\min ) J_{m}(U, V)=\sum_{j=1}^{m} \sum_{i=1}^{e} U_{i j}^{m} d_{i j}^{2}\left(X_{j}, V_{i}\right) \\
d_{i j}\left(X_{j}, V_{i}\right)=\left\|V_{i}-X_{j}\right\|
\end{gathered}
$$

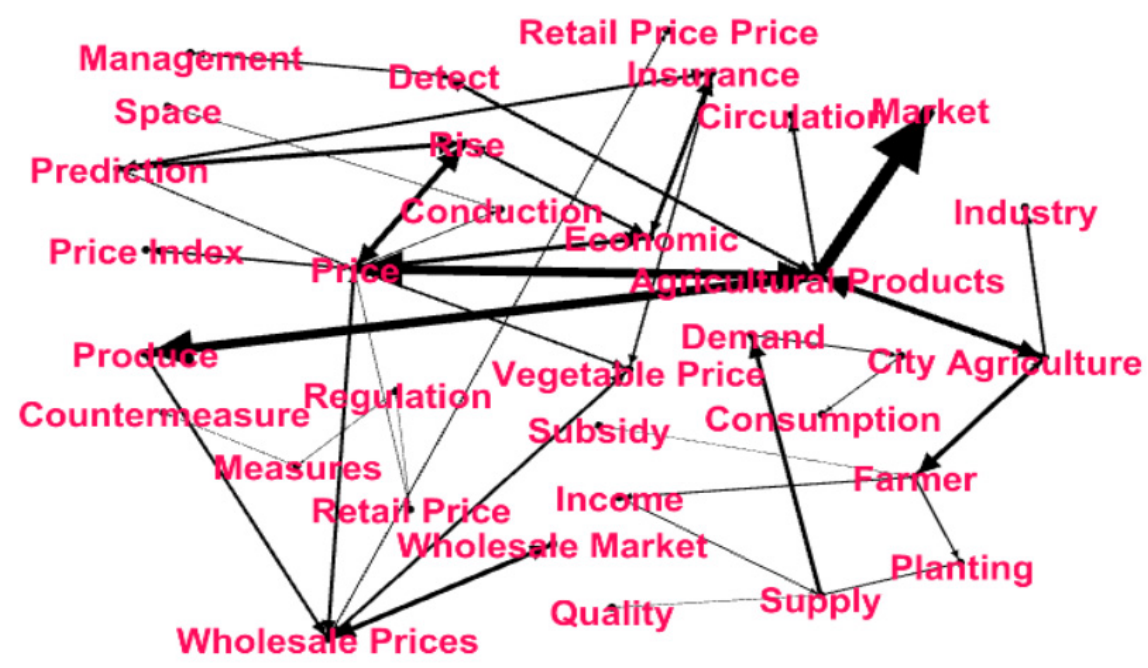

Figure 10. Cluster Analysis Diagram.

From the above cluster analysis graph, it can be seen that there are roughly 6 large centers in the graph, namely "Agricultural Products", "Price", "Produce", "Wholesale 
Prices", "Rise" and "Prediction". There are many connections between the six clusters. On the other hand, this chart can be divided into three sections. One is based on vegetable farmers, which involves planting, supply, income, operation, risk and becoming rich; the other subject is based on consumers. The main body involves rising, consumption, demand, freshness, safety, quality, etc., which reflect the demands of consumers; the last main body is the government-based decision-making department, using a series of methods, such as subsidizing vegetable farmers and providing timely information, formulate relevant policies, etc. to control the drastic fluctuations in vegetable prices.

\section{Comparative Analysis of Domestic and Foreign Literature}

\subsection{Analysis of Vegetable Price Fluctuation and Transmission}

International research has highlighted the asymmetrical nature of vegetable price transmission, hence the need for vegetables to expand distribution channels and for prices to vary across different distribution channels, with vegetable direct sales outlets being price competitive [19]. The price of vegetables is affected by many factors. At a specific point in time, the price will fluctuate with the quality and appearance of the batches sold [20]. Then some scholars have studied the use of new bio-organic fertilizers to improve the quality of vegetables. Improve the competitiveness of products [21]. The reason is that vegetables are perishable, and the transmission speed of vegetables falling is much higher than the transmission speed of rising [22]. The AVTAR model also finds the degree of integration of the more perishable agricultural products market. higher. Vegetable prices are asymmetric in the circulation process [23]. Ronald W. (1982) adopted the "Wolffram" model and found that retail and shipping point prices usually lag behind wholesale price changes [24]. Santeramo (2015) collects and analyzes the European market The price of tomatoes and cauliflower in China has been found to be asymmetrical in spatial price transmission [25]. The marketing efficiency and price difference of the determined marketing channels were analyzed through field investigations, and the results showed that the processing of vegetables can effectively add value to vegetables [22]. Santos et al., (2015) focus on the maximization of vegetable farmers' income, and the study finds that it makes full use of the diverse harvesting period and productivity of crops and rotates different vegetable varieties to increase income [26]. Scholars have found that the GATT has an impact on EU fruit and vegetable policies [27], and then found that seasonal tariff quotas have led to fluctuations in vegetable prices [28]. Therefore, different import and export systems will directly affect the entry of vegetables into the market [29].

In the research on vegetable prices in China, most scholars use the X-12-ARIMA seasonal adjustment model and HP filtering method to analyze vegetable price fluctuations and use this method to analyze the seasonal fluctuations of five major vegetables in Hubei Province from 2000 to 2001. Next, divide it into 6 fluctuation stages; or decompose the wholesale prices of 28 kinds of vegetables in China into 4 kinds of fluctuation types: trend, cycle, season and random, and analyze the fluctuation of each type of vegetable price; or start from the vegetable supply chain [2].

\subsection{Demand Analysis of Green Organic Vegetables}

A great deal of international research on vegetables, focusing on green and organic, is not a bad idea, which is in line with the fact that the value of a commodity lies in its quality [30]. Green, organic, high-quality vegetables meet the needs of new markets, and at the same time, can increase the value of vegetables, thereby increasing the income of vegetable farmers, and promoting the development of the vegetable industry in a more active and healthier direction. By modeling the price and promotion effect of the diffusion process of vegetables, the results show that for retailers, choosing appropriate retail pricing policies to accelerate the diffusion of organic vegetables [31]. Schroeck (2013) found that German consumers are more sensitive to organic vegetables. The demand for vegetables will be higher than the demand for traditional vegetables [32]. It can be seen that most scholars hold a supportive attitude towards green organic vegetables, which 
will be the direction of the future development of the vegetable industry, but we must also give strong support to relevant policies. In the research on green organic vegetables in China, in response to the country's call for rural revitalization, especially the unscientific planting of greenhouse vegetables in some underdeveloped areas has led to greenhouse gas emissions [33], many areas are looking for new ideas and began to produce planned green organic vegetables, vegetable farmers join agricultural cooperatives and sell them through the Internet, bringing good news to many people and consumers. Since the outbreak of new crown pneumonia in the world, the development of the green vegetable industry has been even more stimulated. Through a survey of consumers in Beijing, most people expressed that they are more willing to buy green organic vegetables [34].

\subsection{Forecast and Early Warning Analysis of Vegetable Prices}

International scholars have focused their research on forecasting vegetable prices, through which forecasts facilitate the formulation of policies for governments and enable vegetable farmers to manage their risks in advance and minimize losses. Scholars use the ARIMA model to predict Serbia's prices from 2018 to 2022 [35] and use a hybrid method of STL and ELM to predict the seasonality of vegetable prices in China. The accuracy of their predictions is still relatively high [36]. Paredes-Garcia et al. (2019) implement a vegetable price prediction system to provide information for Mexican farmers to make better decisions [37]. Similarly, Yin et al. (2020) use STL and attention mechanism-based LSTM to predict vegetable prices with small errors [38]. Scholars are based on HP filtering the hybrid neural network structure of the processor [39] predicts the price of vegetables in linear and nonlinear modes, effectively reducing the risk of vegetable farmers; scholars also combine the fruit fly algorithm (FOA) with the induced ordered weighted average (IWOA), improve the prediction accuracy [40], by establishing a seasonal SARIMA model to predict the monthly price of tomato wholesale prices [32]. In addition, some scholars link internet public opinion with vegetable prices, and construct a combined volume through analysis of internet public opinion the mixed prediction model of product neural network and corpus, and eliminate the seasonal effect of price [41], combined with natural language processing (NLP), convolutional neural network (CNN) and classic economic methods, to carry out large-scale public opinion Subject modeling, research shows that online public opinion has an impact on the fluctuation of vegetable prices, which can be used as a potential factor in predicting vegetable prices [42]. In addition, seven indicators are selected using the ICAVP algorithm to establish a better vegetable price early warning system [43].

China has also achieved fruitful results in vegetable price prediction. Some scholars use LSTM, BP and ARIMA models to predict vegetable prices in terms of forecasting methods. In particular, the recently popular BP neural network and wavelet neural network methods have also been widely used in other fields [44], combined with MSE criteria and TSK Fuzzy system, training and learning neural network, to predict the price of vegetables effectively. Some scholars have established a Gaussian regression model based on the dynamic characteristics of genetic algorithms, and the prediction error is small. Even though some achievements have been made in vegetable price forecasting and early warning, there is no unified forecasting method in the industry. The forecast target is only limited to a single region or a single vegetable variety. Therefore, it isn't easy to fit the price forecast of all vegetables. The price warning established The lines are not the same, the early warning systems overlap, and the control measures are not clear, so this is the direction for future scholars.

\subsection{Substitution and Integration Analysis between Vegetables}

The above is a longitudinal study of vegetable price fluctuations over time or a direct exploration of factors that affect vegetable price fluctuations. Scholars at home and abroad also study the substitution effect between different types of vegetables from a horizontal perspective. Kim et al. (2019) investigated the price relationship between organic carrots, tomatoes and lettuce in the United States and extended to the asymmetric price 
transmission between organic vegetables and traditional vegetables, leading to vegetable price fluctuations [45]. The most representative of this research direction in China is the scholar Li Weiwei. Based on the price data of 30 vegetable varieties, a complex network diagram was constructed to explore the correlation and transmission path between the prices of different vegetables and take the Beijing area as an example.

\subsection{Vegetable Price Insurance Analysis}

Vegetable price fluctuations are inevitable, but how to reduce the loss of vegetable farmers and protect their rights and interests? Scholars at home and abroad are also concerned about the research on vegetable price insurance. Scholars conducted research on the main motivations of Chinese farmers for signing contracts and found that it was not to avoid market risks but to seek better quotations and reduce marketing transaction costs [46]. Policy support is needed, and vegetable price insurance is also necessary. In the research on vegetable price insurance in China, relevant scholars used the Copula method to predict the output and price of vegetables, calculate the insurance premium rate generated by the correlation degree, and use the moving coefficient of variation to assess the risk of the vegetable industry. Vegetable farmers effectively Reduce the loss. However, compared with the vegetable insurance system in Europe, America and Japan, China's insurance system is still in the early stage of development, and there are still many problems. It needs to be continuously improved to promote the increase in the rate of insurance for vegetable farmers.

\section{Conclusions and Outlook}

\subsection{Analysis Conclusions}

This paper uses CiteSpace, Python and other software to visually analyze the research on the influence factors of vegetable prices at home and abroad. Based on a large number of Chinese and foreign documents, the research on vegetable prices has always been a hot issue, which is directly related to people's daily life. In general, the perspective of vegetable price research is focused on countries such as the United States, China, Japan and Australia and the themes of research revolve around multiple dimensions such as vegetable price formation mechanisms, production and marketing price comparisons, supply chain relationships and money supply, and the research is homogeneous and specific. This paper describes the progress of vegetable price research in China and other countries as a whole. The three main parts of the paper are described in terms of the collaborative network of authors, institutions and countries, the co-occurrence network of keywords, sources and categories and the co-citation network of references, which ex-plains the internal logical relationships of papers in this research area very well and gives a refreshing impression. At the same time, the innovative synthesis of textual data from all the literature in this paper breaks the limitation of being limited to abstract and keyword information, and further does a cluster analysis to better interpret what the themes are and what are the issues of concern to scholars in the field. Based on the research perspectives of Chinese and foreign scholars, they analyze the influencing factors such as vegetable circulation links, distribution channels, market information, product quality, climate and seasonal change time series. In addition, a small number of scholars pay attention to direct substitution; the integration function analyzes the reasons for vegetable price fluctuations and proposes solutions accordingly. Based on this research, some scholars further predict the future price of vegetables. As far as current technology is concerned, this research is not mature enough, and the accuracy of the prediction needs to be improved. Given the fluctuation of vegetable prices, scholars also focus on agricultural product insurance. However, the agricultural product insurance system is still in its infancy, and fewer vegetable farmers participate in insurance. In the future, it is necessary to strengthen further the construction of the institutional system to make the vegetable industry constitute a system. 


\subsection{Future Research}

In vegetable price research, one is to comprehensively use various analysis methods to improve the accuracy of the research. Chinese and foreign scholars have made rapid progress in the research on the factors affecting vegetable prices, but in a rapidly changing market economy, the influencing factors are also changing. Many scholars only analyze the impact on vegetable prices from a certain angle, ignoring that the reality is the result of the common influence of many factors, and the proportions of various factors in different periods are not the same. This requires further development of new models to make the analysis more precise. It is necessary to pay attention to the fluctuation of vegetables due to time series, involve factors such as climate, vegetable characteristics, money supply, etc., and consider the substitution between different types of vegetables. Integrated influence. In particular, it is necessary to make full use of neural network learning and place it in a simulated world, which can quickly budget the price of future vegetables to provide a better reference for decision-makers. The second is to strengthen the construction of big data on vegetable production, circulation and sales, realize the sharing of vegetable price information between consumers and producers, and reduce information asymmetry. Even though communication technology has alleviated this problem to a certain extent, information asymmetry leads to welfare losses from time to time. When the information is symmetrical, vegetable farmers can reasonably adjust the planting structure of vegetables and set reasonable sales prices. Only then can consumers buy vegetables at moderate prices, and the government can formulate policies that meet the actual conditions and improve the effectiveness of the policies. The third is to increase support for the vegetable industry and focus on promoting the use of vegetable planting insurance. In a market economy, the development of the vegetable industry is difficult and always faces the risk of bankruptcy. Therefore, it is necessary to strengthen the production subsidies for the vegetable industry, train vegetable farmers in a planned way and provide feasible suggestions on the planting structure according to market conditions, which can effectively protect the interests of producers and promote the upgrading and upgrading of the entire vegetable industry. In addition, we must also vigorously support the production of green organic vegetables. There is huge room for development, and further exploration is needed. The fourth is to promote the online sales of vegetables and realize the transformation and upgrading of circulation in a "fixed-point" manner. Now in the golden age of e-commerce development, we can increase the brand building of related vegetables, which is fully beneficial to platforms such as Taobao and JD. Live broadcast of agricultural products, realize zero stores, reduce intermediate links and thus increase the price advantage and adopt one-to-one the model of entering the community, entering the school, entering the enterprise, one area is responsible for the supply of specific vegetables and realizes the professionalization of vegetable production.

Author Contributions: Conceptualization, Y.L. and J.C.; methodology, Y.L.; software, J.L.; validation, H.Y.; formal analysis, H.Y.; investigation, J.L.; resources, Y.L.; data curation, J.L.; writing-original draft preparation, J.L.; writing-review and editing, J.X. and Y.L.; visualization, Y.L.; supervision, J.C.; project administration, Y.L.; funding acquisition, J.C. All authors have read and agreed to the published version of the manuscript.

Funding: This work was supported partly the National Social Science Foundation of China (Project No. 21BGL168), the MOE (Ministry of Education in China) Project of Humanities and Social Sciences (Project No. 20YJC790069), the National Social Science Foundation of China General Program of Art Studies (Project No. 20BG133), the Earmarked Fund for Modern Agro-industry Technology Research System (Project No. CARS-23-F01 and No. CARS-21).

Institutional Review Board Statement: Not applicable.

Informed Consent Statement: Not applicable.

Data Availability Statement: The data presented in this study are available on request from the corresponding author. 
Conflicts of Interest: The authors declare no conflict of interest.

\section{References}

1. Zhen, H.Y.; Gao, W.Z.; Yuan, K.; Ju, X.H.; Qiao, Y.H. Internalizing externalities through net ecosystem service analysis-A case study of greenhouse vegetable farms in Beijing. Ecosyst. Serv. 2021, 50, 101323. [CrossRef]

2. Cao, Y.L.; Mohiuddin, M. Sustainable Emerging Country Agro-Food Supply Chains: Fresh Vegetable Price Formation Mechanisms in Rural China. Sustainability 2019, 11, 2814. [CrossRef]

3. Zhang, X.H.; Qing, P.; Yu, X.H. Short supply chain participation and market performance for vegetable farmers in China. Aust. J. Agric. Resour. Econ. 2019, 63, 282-306. [CrossRef]

4. Burt, R.S. Structural holes and good ideas. Am. J. Sociol. 2004, 110, 349-399. [CrossRef]

5. Hingley, M.; Sodano, V.; Lindgreen, A. Differentiation strategies in vertical channels-A case study from the market for fresh produce. Br. Food J. 2008, 110, 42-61. [CrossRef]

6. Bohall, R.W. Marketing System for Fresh Winter Vegetables-Prices and Performance. J. Am. Soc. Hortic. Sci. 1971, 96, 793-798.

7. Skinner, G.W. Vegetable Supply and Marketing in Chinese Cities. China Q. 1978, 76, 733-793. [CrossRef]

8. Xiao, F.J.; Li, C.Z.; Sun, J.M.; Zhang, L.J. Knowledge Domain and Emerging Trends in Organic Photovoltaic Technology: A Scientometric Review Based on CiteSpace Analysis. Front. Chem. 2017, 5, 67. [CrossRef]

9. Gao, F.-Z.; He, L.-Y.; He, L.-X.; Zou, H.-Y.; Zhang, M.; Wu, D.-L.; Liu, Y.-S.; Shi, Y.-J.; Bai, H.; Ying, G.-G. Untreated Swine Wastes Changed Antibiotic Resistance and Microbial Community in the Soils and Impacted Abundances of Antibiotic Resistance Genes in the Vegetables. Sci. Total Environ. 2020, 741, 140482. [CrossRef]

10. Yao, Y.; Sun, J.; Tian, Y.; Zheng, C.; Liu, J. Alleviating Water Scarcity and Poverty in Drylands through Telecouplings: Vegetable Trade and Tourism in Northwest China. Sci. Total Environ. 2020, 741, 140387. [CrossRef]

11. Gandorfer, M.; Porsch, A.; Bitsch, V. Producer Price Volatility in the German Fruit and Vegetable Industry. Eur. J. Hortic. Sci. 2017, 82, 149-154. [CrossRef]

12. Lan, H.; Dobson, P.W. Healthy Competition to Support Healthy Eating? An Investigation of Fruit and Vegetable Pricing in UK Supermarkets. J. Agric. Econ. 2017, 68, 881-900. [CrossRef]

13. Zhylyevskyy, O.; Jensen, H.H.; Garasky, S.B.; Cutrona, C.E.; Gibbons, F.X. Effects of Family, Friends, and Relative Prices on Fruit and Vegetable Consumption by African Americans. South. Econ. J. 2013, 80, 226-251. [CrossRef]

14. Carter, P.; Gray, L.J.; Troughton, J.; Khunti, K.; Davies, M.J. Fruit and Vegetable Intake and Incidence of Type 2 Diabetes Mellitus: Systematic Review and Meta-Analysis. BMJ 2010, 341, c4229. [CrossRef]

15. Bacus, R.H.; Real, R.R.; Concepcion, S.B.; Montiflor, M.O.; Aguinaldo, R.T. Linking Smallholder Vegetable Producers to High Value Markets: Challenges, Experiences and Lessons from Marketing Clusters in the Southern Philippines. Acta Hortic. 2015, 49-54. [CrossRef]

16. Powell, L.M.; Chriqui, J.F.; Khan, T.; Wada, R.; Chaloupka, F.J. Assessing the Potential Effectiveness of Food and Beverage Taxes and Subsidies for Improving Public Health: A Systematic Review of Prices, Demand and Body Weight Outcomes. Obes. Rev. 2013, 14, 110-128. [CrossRef] [PubMed]

17. Drewnowski, A.; Darmon, N. The Economics of Obesity: Dietary Energy Density and Energy Cost. Am. J. Clin. Nutr. 2005, 82, 265S-273S. [CrossRef]

18. Cassady, D.; Jetter, K.M.; Culp, J. Is Price a Barrier to Eating More Fruits and Vegetables for Low-Income Families? J. Am. Diet. Assoc. 2007, 107, 1909-1915. [CrossRef]

19. Valpiani, N.H.; Wilde, P.E.; Rogers, B.L.; Stewart, H.G. Price Differences across Farmers' Markets, Roadside Stands, and Supermarkets in North Carolina. Appl. Econ. Perspect. Policy 2016, 38, 276-291. [CrossRef]

20. Waugh, F.V. Quality Factors Influencing Vegetable Prices. J. Farm Econ. 1928, 10, 185-196. [CrossRef]

21. Feng, N.-X.; Liang, Q.-F.; Feng, Y.-X.; Xiang, L.; Zhao, H.-M.; Li, Y.-W.; Li, H.; Cai, Q.-Y.; Mo, C.-H.; Wong, M.-H. Improving Yield and Quality of Vegetable Grown in PAEs-Contaminated Soils by Using Novel Bioorganic Fertilizer. Sci. Total Environ. 2020, 739, 139883. [CrossRef]

22. Gills, R.; Sharma, J.P.; Burman, R.R.; Sharma, R.R.; Kar, A. Comparative Analysis of Vegetable Production, Value-Addition and Marketing in National Capital Region. Indian J. Hortic. 2016, 73, 87. [CrossRef]

23. Durborow, S.L.; Kim, S.-W.; Henneberry, S.R.; Brorsen, B.W. Spatial Price Dynamics in the US Vegetable Sector. Agribusiness 2020, 36, 59-78. [CrossRef]

24. Ward, R.W. Asymmetry in Retail, Wholesale, and Shipping Point Pricing for Fresh Vegetables. Am. J. Agric. Econ. 1982, 64, 205-212. [CrossRef]

25. Santeramo, F.G. Price Transmission in the European Tomatoes and Cauliflowers Sectors. Agribusiness 2015, 31, 399-413. [CrossRef]

26. Santos, L.M.R.; Munari, P.; Costa, A.M.; Santos, R.H.S. A Branch-Price-and-Cut Method for the Vegetable Crop Rotation Scheduling Problem with Minimal Plot Sizes. Eur. J. Oper. Res. 2015, 245, 581-590. [CrossRef]

27. Swinbank, A.; Ritson, C. The Impact of the GATT Agreement on EU Fruit and Vegetable Policy. Food Policy 1995, 20, 339-357. [CrossRef]

28. Loginova, D.; Portmann, M.; Huber, M. Assessing the Effects of Seasonal Tariff-rate Quotas on Vegetable Prices in Switzerland. J. Agric. Econ. 2021, 72, 607-627. [CrossRef] 
29. Cioffi, A.; Santeramo, F.G.; Vitale, C.D. The Price Stabilization Effects of the EU Entry Price Scheme for Fruit and Vegetables. Agric. Econ. 2011, 42, 405-418. [CrossRef]

30. Waugh, F. Quality as a Determinant of Vegetable Prices; a Statistical Study of Quality Factors Influencing Vegetable Prices in the Boston Wholesale Market. Am. J. Agric. Econ. 1929, 11, 679. [CrossRef]

31. Yercan, M.; Adanacioglu, H. An Analysis of Tomato Prices at Wholesale Level in Turkey: An Application of SARIMA Model Custos E Agronegocio 2012, 8, 52-75.

32. Schroeck, R. Quality and Endogeneity Issues in Demand Systems: A Comparative Estimation of Price and Expenditure Elasticities of the Demand for Organic and Conventional Vegetables in Germany. Ger. J. Agric. Econ. 2013, 62, 18-38.

33. Gu, J.; Wu, Y.; Tian, Z.; Xu, H. Nitrogen Use Efficiency, Crop Water Productivity and Nitrous Oxide Emissions from Chinese Greenhouse Vegetables: A Meta-Analysis. Sci. Total Environ. 2020, 743, 140696. [CrossRef] [PubMed]

34. Zhang, B.; Fu, Z.; Huang, J.; Wang, J.; Xu, S.; Zhang, L. Consumers' Perceptions, Purchase Intention, and Willingness to Pay a Premium Price for Safe Vegetables: A Case Study of Beijing, China. J. Clean. Prod. 2018, 197, 1498-1507. [CrossRef]

35. Novković, N.; Drinić, L.; Mihajlović, Š.; Vukelić, N.; Ivanišević, D. Price Parities for Vegetables in Serbia-Analysis and Forecasting. Contemp. Agric. 2019, 68, 51-59. [CrossRef]

36. Xiong, T.; Li, C.; Bao, Y. Seasonal Forecasting of Agricultural Commodity Price Using a Hybrid STL and ELM Method: Evidence from the Vegetable Market in China. Neurocomputing 2018, 275, 2831-2844. [CrossRef]

37. Paredes-Garcia, W.J.; Ocampo-Velázquez, R.V.; Torres-Pacheco, I.; Cedillo-Jiménez, C.A. Price Forecasting and Span Commercialization Opportunities for Mexican Agricultural Products. Agronomy 2019, 9, 826. [CrossRef]

38. Yin, H.; Jin, D.; Gu, Y.H.; Park, C.J.; Han, S.K.; Yoo, S.J. STL-ATTLSTM: Vegetable Price Forecasting Using STL and Attention Mechanism-Based LSTM. Agriculture 2020, 10, 612. [CrossRef]

39. Li, Y.; Li, C.; Zheng, M. A Hybrid Neural Network and H-P Filter Model for Short-Term Vegetable Price Forecasting. Math. Probl. Eng. 2014, 2014, 135862. [CrossRef]

40. Li, B.; Ding, J.; Yin, Z.; Li, K.; Zhao, X.; Zhang, L. Optimized Neural Network Combined Model Based on the Induced Ordered Weighted Averaging Operator for Vegetable Price Forecasting. Expert Syst. Appl. 2021, 168, 114232. [CrossRef]

41. Chen, J.; Zhou, H.; Hu, H.; Song, Y.; Gifu, D.; Li, Y.; Huang, Y. Research on Agricultural Monitoring System Based on Convolutional Neural Network. Future Gener. Comput. Syst. 2018, 88, 271-278. [CrossRef]

42. Li, Y.; Zhou, H.; Lin, Z.; Wang, Y.; Chen, S.; Liu, C.; Wang, Z.; Gifu, D.; Xia, J. Investigation in the Influences of Public Opinion Indicators on Vegetable Prices by Corpora Construction and WeChat Article Analysis. Future Gener. Comput. Syst. 2020, 102, 876-888. [CrossRef]

43. Li, Y.; Xia, J.; Li, C.; Zheng, M. Construction of an Early-Warning System for Vegetable Prices Based on Index Contribution Analysis. Sustainability 2015, 7, 3823-3837. [CrossRef]

44. Deng, Y.; Zhou, X.; Shen, J.; Xiao, G.; Hong, H.; Lin, H.; Wu, F.; Liao, B.-Q. New Methods Based on Back Propagation (BP) and Radial Basis Function (RBF) Artificial Neural Networks (ANNs) for Predicting the Occurrence of Haloketones in Tap Water. Sci. Total Environ. 2021, 772, 145534. [CrossRef]

45. Kim, G.; Seok, J.H.; Mark, T.B.; Reed, M.R. The Price Relationship between Organic and Non-Organic Vegetables in the U.S.: Evidence from Nielsen Scanner Data. Appl. Econ. 2019, 51, 1025-1039. [CrossRef]

46. Holly Wang, H.; Zhang, Y.; Wu, L. Is Contract Farming a Risk Management Instrument for Chinese Farmers? China Agric. Econ. Rev. 2011, 3, 489-505. [CrossRef] 